\title{
Studies Thermodynamical Stability of Complexes of Rare Earth Metal Ions with Substituted Pyrazole
}

\author{
A. B. Naik ${ }^{1, *}$, M. L. Narwade ${ }^{2}$ \\ ${ }^{1}$ Physical Chemistry laboratory, Department of Chemical Technology, SGB Amravati University, Amravati-444602 (MS) India \\ ${ }^{2}$ Department of Chemistry, Vidyabharati Mahavidyalaya, Amravati-444602 (MS) India \\ *Corresponding Author: anilnaik@sgbau.ac.in
}

Copyright (C) 2013 Horizon Research Publishing All rights reserved.

\begin{abstract}
The stability constants of 1-phenyl-3-(2-hydroxy-4-methylphenyl)-5-methylpyrazole (PHMPMPz) and their complexes with Pr (III) and Sm (III) metal ions have been determined in $70 \% \mathrm{v} / \mathrm{v}$ dioxane-water media at different ionic strength $(0.02,0.04,0.06,0.08,0.1)$ mol. $\mathrm{dm}^{-3}$ at $300.15 \mathrm{~K}$ by $\mathrm{pH}$ metry method. The $\mathrm{pK}$ and $\log \mathrm{K}$ values decrease with increase in ionic strength of medium, which indicated the opposite charges on reacting species. The values of stability constants for Sm (III) were greater than $\operatorname{Pr}$ (III) metal ion. The thermodynamic stability constants at zero ionic strength have also been determined.
\end{abstract}

Keywords Pyrazole, ionic strength, stability constant, $\mathrm{pH}$

\section{Introduction}

Dissociation of organic acids and their interaction with metal ions (complex formation) may be extremely sensitive to ionic strength of the medium [1]. If charges on the reacting species are opposite then there is a decrease in the reaction rate with increasing ionic strength (IS) whereas if the charges are identical, an increase in the reaction rate will occur while one of the reactant charge is less the reaction rate does affect by ionic strength of the medium [2]. Ionic strength measures the intensity of an electric field of solution due to the presence of ions in a solution. Ionic strength of medium affects the rate at which ions react with each other and to extent the reaction occurs [3]. High ionic strength reactions are found all around us, from industrial reactions that are carried out at high concentrations to ensure increased productivity to biochemical processes that occur at low or high $\mathrm{pH}$. Indeed, practically every solution based reaction of importance deviates from ideality to some extent. The ionic strength data also used to study the correct mechanism of the complexation reaction [4]. The thermodynamic properties of electrolyte solutions can be studied from long range interactions between ion and solvent molecules. Number of workers $[5,6]$ reported the influence of ionic strength on the organic compounds with metal ions.

Heterocyclic compounds provide a great synthetic and structural versatility due to their having a number of potential substitution positions. Furthermore heteroatoms offer the possibility of several modes of coordination [7]. The pyrazole moiety is present in a large number of biologically active compounds which find wide applications in pharmaceuticals [8] and agro- chemical industries [9]. Numerous compounds containing pyrazole moiety have shown exhibit analgesic, anti-inflammatory, antihelmintic, anti- bacterial, hypoglycemic, antiluekemic and anti- fungal activity [10-13]. The rare earth elements play a significant role in the development of our scientific, everyday life and industrial life [14]. More explicitly, in the previous decades their use in various organic technical processes led to a rapid growth especially in the field of complexes. In recent years the luminescence properties of rare metal complexes with different $\beta$-diketones have been widely studied due to their use in fabrication of polymer light emitting diodes to enable low cost, full color, flat panel displays. The pyrazoles and its derivatives have long been known for their strong complex forming ability. The studies on complex formation by tripositive rare earth ions with biologically important ligands are in progress because of their role in biological processes.

To the best of our knowledge, we explicitly study the effect of ionic strength on complex equilibria and ascertain the thermodynamic association and dissociation stability constants of the metal-ligand complex with rare earth metal ions. The interaction between rare earth metal cations viz. $\mathrm{Sm}$ (III), Pr (III) and PHMPMPz anion showed a complexation reaction.

\section{Materials and Methods}

The stock solution of PHMPMPz $\left(4.0 \times 10^{-2} \mathrm{~mol} . \mathrm{dm}^{-3}\right)$ was prepared by dissolving the requisite amount of ligand in the minimum volume of dioxane subsequently diluted to the final volume. Nitrates of rare earth metal ions (Sigma-Aldrich) were used to prepared metal solutions (1.0 x $10^{-2}$ mol. $\mathrm{dm}^{-3}$ ) and were standard- ized by the EDTA 
titration method [15]. The stock solution of perchloric acid was prepared and used after standardization [16]. The ionic strength $(0.02,0.04,0.06,0.08$ and 0.1$) \mathrm{mol} . \mathrm{dm}^{-3}$ was maintained constant by using sodium perchlorate solutions. The carbonate free sodium hydroxide solution $(0.1071 \mathrm{~mol}$. $\mathrm{dm}^{-3}$ ) was prepared by Vogel's method [17].

The $\mathrm{pH}$ of solution was measured with EQUIP- TRONICS (Model EQ-614) equipped with combined electrode and magnetic stirrer $\mathrm{pH}$ meter model (accuracy \pm 0.005 units) with a combined glass electrode assembly. The instrument could read $\mathrm{pH}$ in the range 0.00 to 14.00 in steps of 0.005 . This $\mathrm{pH}$ meter has a built an internal electronic voltage supply with temperature compensator covering the range 0 to $100{ }^{0} \mathrm{C}$. The Instrument was calibrated before each titration with an aqueous standard buffer solution of $\mathrm{pH}, 4.20$ (phthalate buffer), 7.00 and 9.10 (borate buffer) prepared from a 'Qualigens' buffer tablets.

The $\mathrm{pH}$ metric titration of acid, ligands and metal complexes against standard carbonate free sodium hydroxide $\left(0.1071 \mathrm{~mol}^{\mathrm{dm}}{ }^{-3}\right)$ using Calvin-Bjerr- um [18] and Calvin-Wilson $\mathrm{pH}$ titration techniques already reported [19]. The proton-ligand constants were calculated by using the Irving- Rossotti method [20, 21]
The proton-ligand stability constants for the system were determined at various ionic strengths are shown in table 1 . It may be inferred from experimental data that the $\mathrm{pK}$ values decreases with rise in ionic strength of the medium which in accordance with Debye-Hukel theory [22]. It is indicates that, there is increase in hydrogen ion concentration upon increase in ionic strength of medium. Table 1. Proton-ligand stability constants of PHMPMPz at various Ionic strengths.

The $\mathrm{pK}$ and $\log \mathrm{K}$ are employed to calculate the thermodynamic constant at zero ionic strength by using Bronsted equation;

$$
\begin{aligned}
& p K=p K^{0}-A \Delta Z^{2} \sqrt{\mu} \\
& \log K=\log K^{0}+A \Delta Z^{2} \sqrt{\mu}
\end{aligned}
$$

Where $\Delta Z^{2}=$ difference in the square of the charges of product and reactant ion. The value of $\mathrm{A}$ was taken equal to $0.5161[23]$.

Thermodynamic proton-ligand stability constants, $\mathrm{pK} 0$ (shown in table 2) were determined at zero ionic strength from the plot of $\mathrm{pK}$ versus $\sqrt{ }_{\mu}$ and $\sqrt{\mu} /(1+\sqrt{\mu})$ by extrapolating the curves to zero ionic strength in fig. 1 .

\section{Result and Discussion}

Table 1. Proton-ligand stability constants of PHMPMPz at various Ionic strengths

\begin{tabular}{|c|c|c|c|c|}
\hline IS & $\sqrt{\mu}$ & $\sqrt{\mu} /(1+\sqrt{\mu})$ & $\sqrt{\mu} /(1+\sqrt{\mu})-0.3 \sqrt{\mu}$ & $\mathrm{pK}$ \\
& & & & \\
\hline 0.02 & 0.1414 & 0.1238 & 0.0813 & 11.60 \\
\hline 0.04 & 0.2000 & 0.1666 & 0.1066 & 11.26 \\
\hline 0.06 & 0.2449 & 0.1967 & 0.1232 & 10.97 \\
\hline 0.08 & 0.2828 & 0.2204 & 0.1355 & 10.73 \\
\hline 0.10 & 0.3162 & 0.2402 & 0.1453 & 10.48 \\
\hline
\end{tabular}
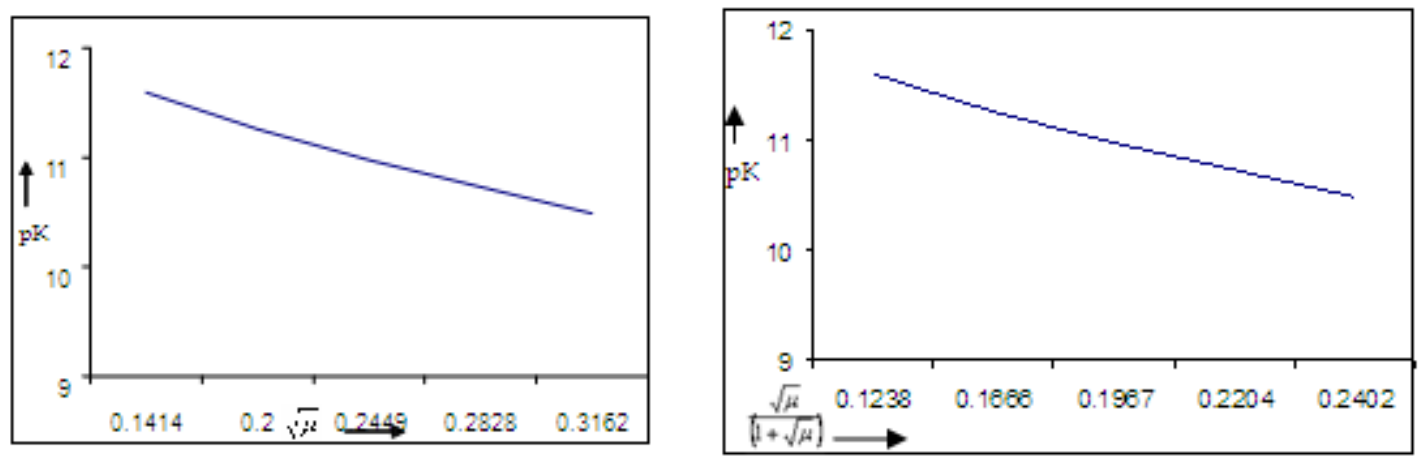

Figure 1. Thermodynamic proton-ligand stability constant $\mathrm{pK} V s \sqrt{\mu}$ and $\sqrt{\mu} /(1+\sqrt{\mu})$

Table 2. Thermodynamic Dissociation Constants $\left(\mathrm{pK}^{0}\right)$ at Zero Ionic strength

\begin{tabular}{|c|c|}
\hline Plots & $\mathrm{pK}^{0}$ for PHMPMPz \\
\hline $\mathrm{pK} V s \sqrt{\mu}$ & 11.66 \\
\hline $\mathrm{pK} V s \sqrt{\mu} /(1+\sqrt{\mu})$ & 11.80 \\
\hline $\mathrm{pK} V s \sqrt{\mu} /(1+\sqrt{\mu})-0.3 \sqrt{\mu}$ & 11.98 \\
\hline
\end{tabular}


Table 3. Thermodynamic Association constants $\left(\log \mathrm{K}^{0}\right)$ from various plots

\begin{tabular}{|c|c|c|}
\hline \multirow{2}{*}{ Plots } & \multicolumn{2}{|c|}{$\log ^{0}$} \\
\cline { 2 - 3 } & $\operatorname{Pr}$ (III)-PHMPMPz & Sm (III)-PHMPMPz \\
\hline $\log \mathrm{K}_{1} V s \sqrt{\mu}$ & 12.60 & 11.20 \\
\hline $\log \mathrm{K}_{1} V s \sqrt{\mu} /(1+\sqrt{\mu})$ & 11.95 & 11.00 \\
\hline $\log \mathrm{K}_{1} V s \sqrt{\mu} /(1+\sqrt{\mu})-0.3 \sqrt{\mu}$ & 11.60 & 10.75 \\
\hline $\log \mathrm{K}_{2} V s \sqrt{\mu}$ & 10.40 & 8.40 \\
\hline $\log \mathrm{K}_{2} V s \sqrt{\mu} /(1+\sqrt{\mu})$ & 9.35 & 7.60 \\
\hline $\log \mathrm{K}_{2} V s \sqrt{\mu} /(1+\sqrt{\mu})-0.3 \sqrt{\mu}$ & 8.00 & 7.30 \\
\hline
\end{tabular}

Table 4. System of $\mathrm{pK} V_{s} \sqrt{\mu}$ and $\mathrm{pK} V_{s} \sqrt{\mu} /(1+\sqrt{\mu})$

\begin{tabular}{|c|c|c|c|c|c|}
\hline \multirow{2}{*}{ System } & \multirow{2}{*}{ System } & \multicolumn{2}{|c|}{$\mathrm{pK} V s \sqrt{\mu}$} & \multicolumn{2}{c|}{$\mathrm{pK} V s \sqrt{\mu} /(1+\sqrt{\mu})$} \\
\cline { 3 - 6 } & & Slope & $\Delta \mathrm{Z}^{2}$ & Slope & $\Delta \mathrm{Z}^{2}$ \\
\hline \multirow{3}{*}{$\operatorname{Pr}(\mathrm{III})-\mathrm{PHMPMPz}$} & $\log \mathrm{K}_{1}$ & 17.81 & 34.50 & 26.69 & 51.72 \\
\cline { 2 - 6 } & $\log \mathrm{K}_{2}$ & 31.33 & 61.71 & 48.01 & 93.04 \\
\hline \multirow{2}{*}{ Sm (III)-PHMPMPz } & $\log \mathrm{K}_{1}$ & 10.55 & 20.44 & 15.62 & 30.27 \\
\cline { 2 - 6 } & $\log \mathrm{K}_{2}$ & 11.39 & 22.07 & 40.40 & 78.29 \\
\hline
\end{tabular}

Table 5. Probable Reaction Mechanism and $\Delta Z^{2}$ Values

\begin{tabular}{|c|c|c|c|c|}
\hline \multirow{2}{*}{ System } & \multirow{2}{*}{ Constant } & \multirow{2}{*}{ Reaction Equilibria } & \multicolumn{2}{|c|}{ Observed $\Delta Z^{2}$} \\
\hline & & & Expected & Observed \\
\hline PHMPMPz & $\mathrm{pK}$ & $H L^{-} \leftrightarrow H^{+}+L^{-}$ & 2.0 & -14.18 \\
\hline Pr(III)-PHMPMPz & $\log \mathrm{K}_{1}$ & $\operatorname{Pr}^{3+}+L^{-} \leftrightarrow(\operatorname{Pr} L)^{2+}$ & -6.0 & -32.29 \\
\hline Pr(III)-PHMPMPz & $\log \mathrm{K}_{2}$ & $(\operatorname{Pr} L)^{2+}+L^{-} \Leftrightarrow\left(\operatorname{Pr} L_{2}\right)^{+}$ & -4.0 & -45.21 \\
\hline Sm(III)-PHMPMPz & $\log \mathrm{K}_{1}$ & $S m^{3+}+L^{-} \Leftrightarrow(S m L)^{2+}$ & -6.0 & -35.98 \\
\hline Sm(III)-PHMPMPz & $\log \mathrm{K}_{2}$ & $(S m L)^{2+}+L^{-} \Leftrightarrow\left(S m L_{2}\right)^{+}$ & -4.0 & -1.72 \\
\hline
\end{tabular}

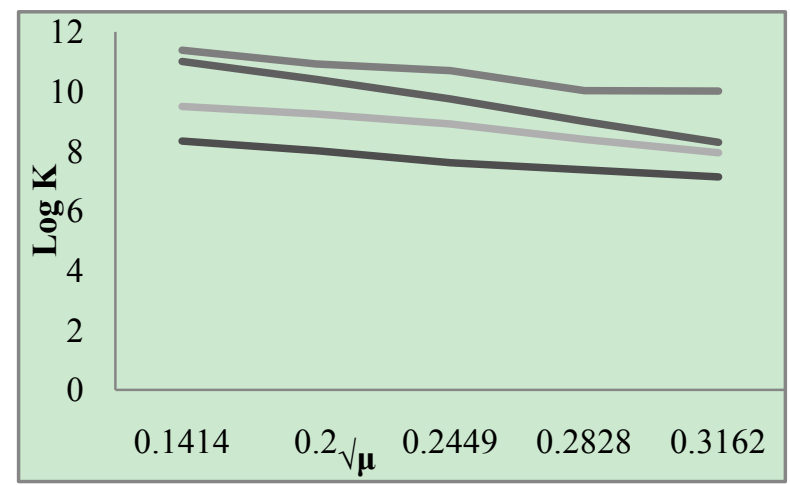

Figure 2. $\log \mathrm{K}$ versus $\sqrt{\mu}$

The plot of $\log \mathrm{K}$ versus $\sqrt{\mu}$ gave straight line over the entire range of ionic strengths for metal complexes are shown in fig. 2. The $\log \mathrm{K}$ values decreases with increase ionic strength of the medium $[24,25]$ which is concordance with Debye-Hukel limiting law. It means that Bronsted relationship is valid for the dissociation of ligand and complex equilibria of chelates. The difference in the $\log \mathrm{K}_{1}$ and $\log \mathrm{K}_{2}$ is small which is due to the simultaneous formation of complexes. The thermodynamic metal-ligand stability constants are reported in Table 3. Literature survey reveals that $\log \mathrm{K}$ versus $\gamma_{\mu}$ plots are generally linear up to $0.1 \mathrm{M}$ ionic strength.

The values $\Delta Z^{2}$ were calculated from the slopes of the straight lines. The different possible reactions observed and expected values of $\Delta Z^{2}$ for corresponding dissociation or association equilibria are represented in table 4 . The observed $\Delta Z^{2}$ values, in all these cases are different than expected. These values do not interfere, give conclusion evidence regarding to the magnitude of charge of reacting species except the information that these are oppositely charged.

\section{Conclusions}


The stability constants of complexes were determined $\mathrm{pH}$ metrically in $70 \%$ dioxane-water media at $300.15 \mathrm{~K}$ with varying the ionic strengths $(0.02,0.04,0.06,0.08$ and 0.1$)$ mol.dm ${ }^{-3} \mathrm{NaClO}_{4}$. The Calculated values of stability constant at various ionic strengths are high. The complexes of PHMPMPz with $\operatorname{Pr}(\mathrm{III})$ and $\mathrm{Sm}(\mathrm{III})$ is quite stable at entire range of ionic strength. The values of thermodynamic parameters are nearly same from all plots was good agreement of results.

\section{REFERENCES}

[1] S. D. Deosarkar, A. B. Kalambe, V. J. Thakare, S. G. Wanale, V. V. Hiwase. Potentiometric studies on electrolyte effect on complex equilibria of some substituted 5-(2-hydroxy phenyl) pyrazoles, Der Pharma Chemica., vol. 3, no. 6, 75-83, 2011.

[2] P. Atakin. J. D. Paula, Physical Chemistry, VIIth Ed. Oxford, 2002.

[3] I. N. Levine. Physical Chemistry, VIth ed. McGraw Hill, NY, 2009.

[4] K. Majleshi, K. Zare, F. Teimouri. Ionic strength dependence of formation constants, protonation and complexation of Nitrilotriacetic acid with Molybdenum (VI), J. Chem. Eng. Data., 48, 680-683, 2003.

[5] J. P. Nethete, G. P. Waghulade, A. N. Sonar. Influence of ionic strength on the thermodynamic parameters of substituted heterocyclic drug with Ce(III), Gd(III) complexes, Ultra Chem., vol. 8, no. 2, 239-242, 2012.

[6] F. Gharib, K. Zare. Ionic strength dependence of formation constants: complexation of Mo (VI) with aspartic acid, J. Chem. Eng. Data., 46, 1140-1144, 2001.

[7] A. B. Naik. Spectrophotometric studies of Dy(III), Nd(III), $\mathrm{Sm}(\mathrm{III})$ and $\mathrm{Tb}(\mathrm{III})$ complexes with substituted pyrazole, World J. of Chem., vol.6, no.2, 118-121, 2011.

[8] K. Sharma, R. Jain. Synthesis, reaction and anthelmintic activity of 1-[benzimidazol-2-yl-]-4-formyl-3-[2'(-substituted phenyl) indole-3-yl] pyrazole, Ind. J. Chem., 51B, 1462 $-1469,2012$.

[9] M. Rahimizadeh, M. Pordel, M. Bakavoli, S. Rezgeian, A. Sadghian. Synthesis and antibacterial activity of some new derivatives of pyrazole, World. J. Microbiol. Biotechnol., 26, 317-321, 2010.

[10] J. P. Vors, V. Gerhaud, N. Gabas, J. P. Canselier, N. Jagerovic, M. L. Jimeno, J. Elguero. The structure of the agrochemical fungicidal 4-chloro-3-(3,5-dichlorophenyl)-1H-pyrazole (RP A 406 194) and related compounds, Tetrahedron, vol. 59, no. 4, 555- 560, 2003.
[11] J. E. Ancel, L. Elkaim, A. Gadras, L. Grimand, N. K. Jana. Studies towards the synthesis of fipronil analogous improved decarboxylation of hydazonoacid derivatives, Tetrahedron Lett., Vol. 43, no. 46, 8319-8321, 2002.

[12] A. A. Bekhit, T. A. Aziem. Design, synthesis and biological evaluation of some pyrazole derivatives as antiinflammotry antimicrobial agent, Biorg. Med. Chem., 12, 1935-1945, 2000 .

[13] P. G. Baraldi, P. Cozzi, C. Geroni, N. Mongelli, R. Romagnoli, G. Spalluto. Cinnamoyl nitrogen mustard derivatives of pyrazole analogues of tallimustine modified at the amidino moiety: design, synthesis, molecular modeling and antitumor activity studies, Biorg. Med. Chem., 7, 251-261, 1999 .

[14] R. Anwander. Top. Orgametallic Chem., Springer Verlag, Berline, Hersdelberg, New York, 1999.

[15] A. I. Vogel. A Text Book of Quantitative Inorganic Analysis, 3rd ed. Longman: London, 1975.

[16] A. I. Vogel's. A Text Book of Quantitative Chemical Analysis, 6th ed., Pearson, 2003.

[17] A. I. Vogel's. A Text Book of Quantitative Inorganic Analysis, 4rd ed. Longman, London, 1978.

[18] J. Bjerrum. Metal Ammine formation in Aqueous Solution, P. Haase and Son, Copenhagen, 1941.

[19] A. B. Naik, M. L. Narwade. Studies on formation constants of the complexes of substituted pyrazoles with some lanthanide metal ions and influence of ionic strengths on complex equilibria in $70 \%$ dioxane-water mixture $\mathrm{pH}$-metrically, Russian J. Coordination Chem., vol. 35, no. 12, 932-937, 2009.

[20] H. M. Irving and H. S. Rossotti. The Method for computing successive stability constants from experimental formation curves, J. Chem. Soc., 3397-3405, 1953.

[21] H. M. Irving and H. S. Rossotti. The calculation of formation of curves of metal complexes from $\mathrm{pH}$ titration curves in mixed solvents, J. Chem. Soc., 2904-2910, 1954.

[22] A. S. El-Sherif. Potentiometric determination stability constants of trimethyltin(IV) chloride complexes with Imino-bis (methylphosphonic acid) in water and dioxanewater mixture, J. Solution Chem., 41, 392-409, 2012.

[23] F. Frank, D. S. G. Ives. Physico-chemical process in mixed solvents, Heinmann Ed. Books Ltd, London, 145, 1969.

[24] K. J. Laidler, Chemical Kinetic, Pearson 3rd ed, 197, 2004.

[25] V. D. Athawale, V. Lele. Stability constants and thermodynamic parameters of complexes of lanthanide ions and ( \pm )-Norvaline, J. Chem. Eng. Data., vol. 41, no.5, 1015-1019, 1996. 